\title{
ANÁLISE DOS SISTEMAS DE INFORMAC̣ÃO DOS PONTOS DE ÔNIBUS DA CIDADE DE MACEIÓ - AL
}

Kalana Barros Lins

Maria Eduarda Ramos Cavalcanti Rosa

\begin{abstract}
Resumo: Dentro do campo do design há um segmento chamado de design de informação, o qual se insere o estudo dos sistemas de informação que é constituído por múltiplos dados, os quais podem se referir desde peças gráficas até mesmo dispositivos táteis. Esses têm uma relevância direta na relação entre produto-usuário, de modo a facilitar e permitir a atividade de modo satisfatório. Nesta elaboração acadêmica foi realizado um estudo de caso dos sistemas de informação dos pontos de ônibus da cidade de Maceió - AL, por ser um objeto de estudo que atende a maior parte da população que se locomove por meio do transporte público. Esse artigo visa perceber e discutir como que o design da informação pode contribuir com a acessibilidade e usabilidade dos usuários de transportes viários.
\end{abstract}

Palavras-chave: pontos de ônibus, design, informação, usuário, Maceió - AL

\section{INTRODUÇÃO}

Desde o último século nossos olhos são receptores de diversas imagens. Elas são muitas vezes captadas pelo nosso cérebro, mas passam despercebidas para nós. Além de experiências visuais no cotidiano, as pessoas passam por experiências sensoriais de diversas maneiras, sejam elas táteis, auditivas, olfativas, etc. Tais experimentos podem ser diferenciados por cores, letras, formatos e texturas.

No design, há uma área específica que estuda todos estes sistemas supracitados. Segundo Alice Twemlow (2007), o design da informação tem como princípio constituir um corpo de dados complexos compreensíveis e imediatamente acessíveis às suas audiências. Dessa forma, esses dados, estão presentes em um sistema de informação o qual deve ser de fácil compreensão para o público que almeja ser alcançado.

Segundo Bedrossian (2008), as novas especializações no campo do design surgem em resposta às mudanças culturais e econômicas da sociedade. Uma delas diz respeito à transmissão de mensagens e informações por meio do ambiente construído, tratando-se de várias camadas da comunicação que ajudam a moldar nossa compreensão e senso de lugar. Dul \& Weedmeester (2004) comentam que, tanto no trabalho como em situações cotidianas as condições de insegurança, desconforto e ineficiência são eliminadas quando adequadas às capacidades e limitações físicas do homem, onde também devem ser consideradas as questões sensoriais pela importância no desempenho humano na execução de tarefas.

lida (2005) considera que para a usabilidade atingir de maneira satisfatória o público alvo, devem-se considerar algumas questões como a cultura onde o indivíduo 
está inserido e o seu repertório. Entretanto, é perceptível a demanda contemporânea da adequação do design à acessibilidade, de modo que as sinalizações devem procurar atender a todos os públicos.

Neste artigo serão usados como objeto de estudo dois pontos de ônibus da cidade de Maceió, que serão analisados de acordo com o sistema de informação que é passado para a população, o que é compreendido, e de que modo podem ser melhorados, do modo como foram criados e se atendem a toda a população de fato. As situações a serem abordados neste estudo de caso serão a tipografia e cores utilizadas nos pontos de ônibus, as sinalizações e elementos interativos que compõe esse sistema, fazendo uma relação com a importância do usuário neste contexto.

\section{DESENVOLVIMENTO}

\subsection{Sistemas de Informação para a Usabilidade}

A ISO 9241-11 define usabilidade como a informação necessária a ser considerada na especificação ou avaliação em termos de desempenho e satisfação do usuário. Segundo Norman (2002), o design ajuda o usuário a interagir com o objeto e seus sistemas, onde o produto deve indicar o mapeamento entre as ações pretendidas e as operações concretas. A visibilidade indica distinções cruciais, de modo que o receptor possa distinguir os diferentes elementos, sendo a falta dela um dos fatores que torna tantos sistemas difíceis de serem percebidos e operados (NORMAN, 2002, p.18). Consoante, lida (2005), diz que para uma boa transmissão da informação ou comunicação, é necessário haver uma fonte, um meio e um receptor, onde o receptor recebe e interpreta corretamente a mensagem que a fonte desejava transmitir (IIDA, 2005, p. 257).

Entretanto, um dispositivo de informação não realiza necessariamente a transmissão de informações, mas sim a função de emitir estímulos que detenham significado ou não para o receptor, onde a importância da percepção e interpretação correta desses estímulos está muitas vezes relacionada a algumas características neles apresentadas como a frequência, intensidade e duração (IIDA, 2005). A NBR 9050 (2004), norma de acessibilidade a mobiliário, espaços e equipamentos urbanos, divide o uso da comunicação como: visual, tátil e sonora e de sinalização em mobiliários, como permanente, devendo ser utilizada para identificar seus comandos. Sabendo disso, elementos como tipografia, cor, pictogramas, Braille, dentre outros são importantes para comunicar às diversas pessoas que fazem o uso dos espaços públicos.

Para compreender a mensagem visual pode-se dividi-la em informação, ou seja, o conteúdo que a mensagem quer transmitir, e o suporte visual, o que "é visível" na mensagem, como por exemplo: cor, textura, forma entre outros (MUNARI, 1977). Um suporte bem escolhido é o que facilita a transmissão da mensagem, sendo responsável pela eficácia ou não da mensagem ser entendida pelo receptor, e isto pode ocorrer por meio de fatores como usabilidade, legibilidade, imagens, diagramação, tipografia e toda manipulação das técnicas visuais. De acordo com Saltz (2010), em relação à tipografia o uso da neutralidade se faz conveniente, e muitas vezes se faz necessária a diferenciação por tamanho, por exemplo, para hierarquizar algumas informações mais importantes. Já, segundo Banks (2007) a cor, pode comunicar complexas interações de associação e simbolismo ou uma simples mensagem, de maneira mais clara que as palavras.

Sendo assim, de acordo com Bonnici (2000), a linguagem visual se comunica através de mensagens diversas que codificam uma imagem e às vezes se apoiam em aparatos verbais. Entretanto, segundo Munari (1977), o suporte visual inclui vários elementos além da imagem e tornam a mensagem mais visível. Sendo assim, o trabalho do designer 
é desenvolver experiências visuais sobre o uso de texturas, formas, estruturas e movimentos, utilizando cor e contraste.

\subsection{Estudo de Caso}

Neste trabalho serão analisados quatro quesitos de dois pontos de ônibus da cidade de Maceió, o primeiro que está localizado na Avenida Durval de Góes Monteiro, no bairro do Tabuleiro do Martins, o qual será nomeado no decorrer deste estudo como "ponto azul” (Figura 1), e o segundo que está localizado na Avenida Menino Marcelo, no bairro da Serraria, o qual será nomeado como "ponto branco" (Figura 2).

Figura 1- Ponto de ônibus na Avenida Durval de Góes Monteiro. Fonte: Elaborado pelo autor, 2017.

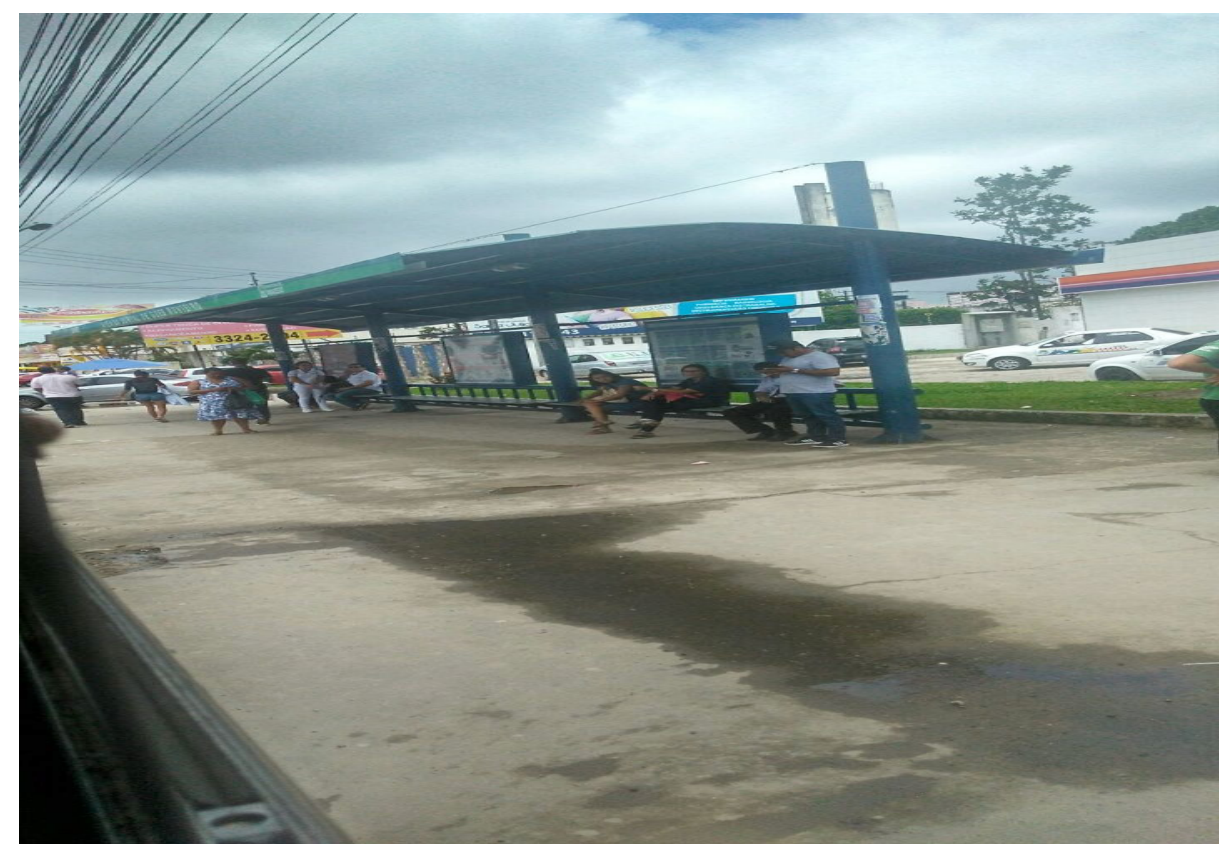

Figura 2- Ponto de ônibus na Avenida Menino Marcelo. Fonte: Elaborado pelo autor, 2017.

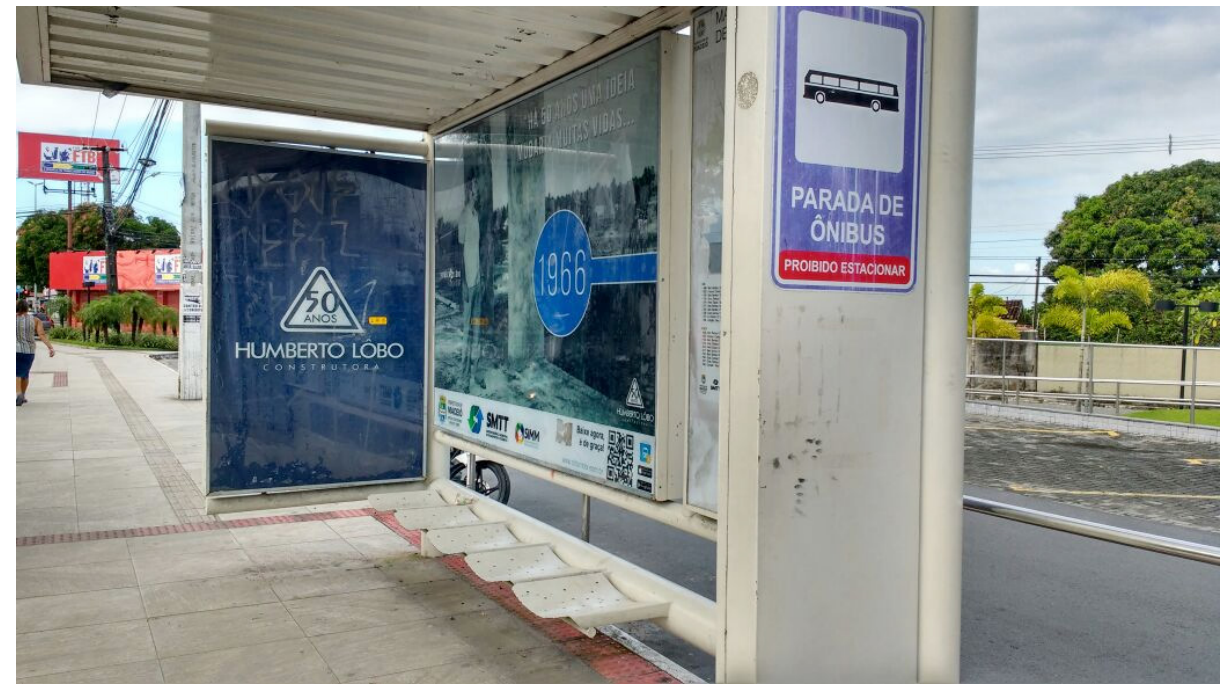

Foi observado que em ambos os pontos que há distinção entre tipografias, cores, sinalizações e elementos interativos, e por esse motivo foram essas conjunturas estudadas neste trabalho para visualização da sua eficácia na comunicação ao receptor.

Como dito anteriormente a tipografia é um dos elementos importantes na percepção da informação, onde de acordo com Saltz (2010), "a neutralidade possui uma elegância moderada, a qual pode ser tanto moderna como clássica (dependendo de como os tipos 
com e sem serifas forem usados) e como são aplicados para acomodar o conteúdo". Segundo Paulo Heitlinger, a tipografia sans serif teve origem na Alemanha por volta de 1820, que inicialmente eram chamadas de Steinsschriften ou Grotesk, por serem ausentes de estética para seus compositores. Já as letras serifadas ou egípcias são consideradas mais legíveis no momento da leitura, pois tradicionalmente essas eram as tipografias mais utilizadas durante muito tempo, o que pode ser mais bem compreendido na Figura 3.

Figura 3-Diferença entre letras com e sem serifa. Fonte Next Ecommerce, adaptado pelo autor.

\section{$\mathrm{AaBbCc} \mathrm{c}^{\text {rorite ex enetro }}$

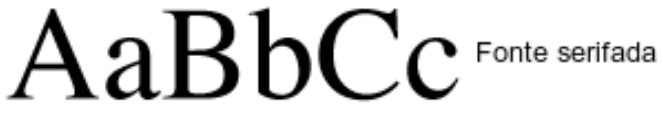 $\mathrm{AaBbCc}$ santsensuremero}

A utilização tipográfica ainda divide opiniões, sendo para alguns designers o uso de tipografias sem serifa uma falta de personalidade, como é o caso da "Helvética" que é uma tipografia que representa a neutralidade (SALTZ, 2010, P. 26). Entretanto pessoas com baixa compreensão visual refinada têm preferência por fontes limpas e simples, onde elas não consigam confundir o formato das letras pela estética diferenciada. Seguindo esse pensamento, percebe-se que a tipografia colocada em ambos os pontos de ônibus está coerente com a preferência do público majoritário que frequenta o espaço, permitindo uma leitura simples eficiente a maior parte das pessoas.

Outro ponto importante, contudo, é a diferenciação entre os tamanhos das tipografias, onde segundo Saltz (2010) o tamanho é um grande indicador de hierarquia e importância da informação. Esta hierarquia pode ser observada no ponto azul onde está escrito o nome das linhas dos ônibus em letras maiores e o trajeto percorrido pelo ônibus em letras menores (Figura 4). Já no ponto branco essa hierarquização é exposta em letras maiúsculas sobre o título do mapa de itinerários e as letras minúsculas são usadas para mostrar os nomes das linhas que passam por aquele ponto (Figura 5).

Figura 4- Tipografia usada no ponto azul. Elaborada pelo autor, 2017. Figura 5- Tipografia usada no ponto branco. Elaborado pelo autor, 2017.
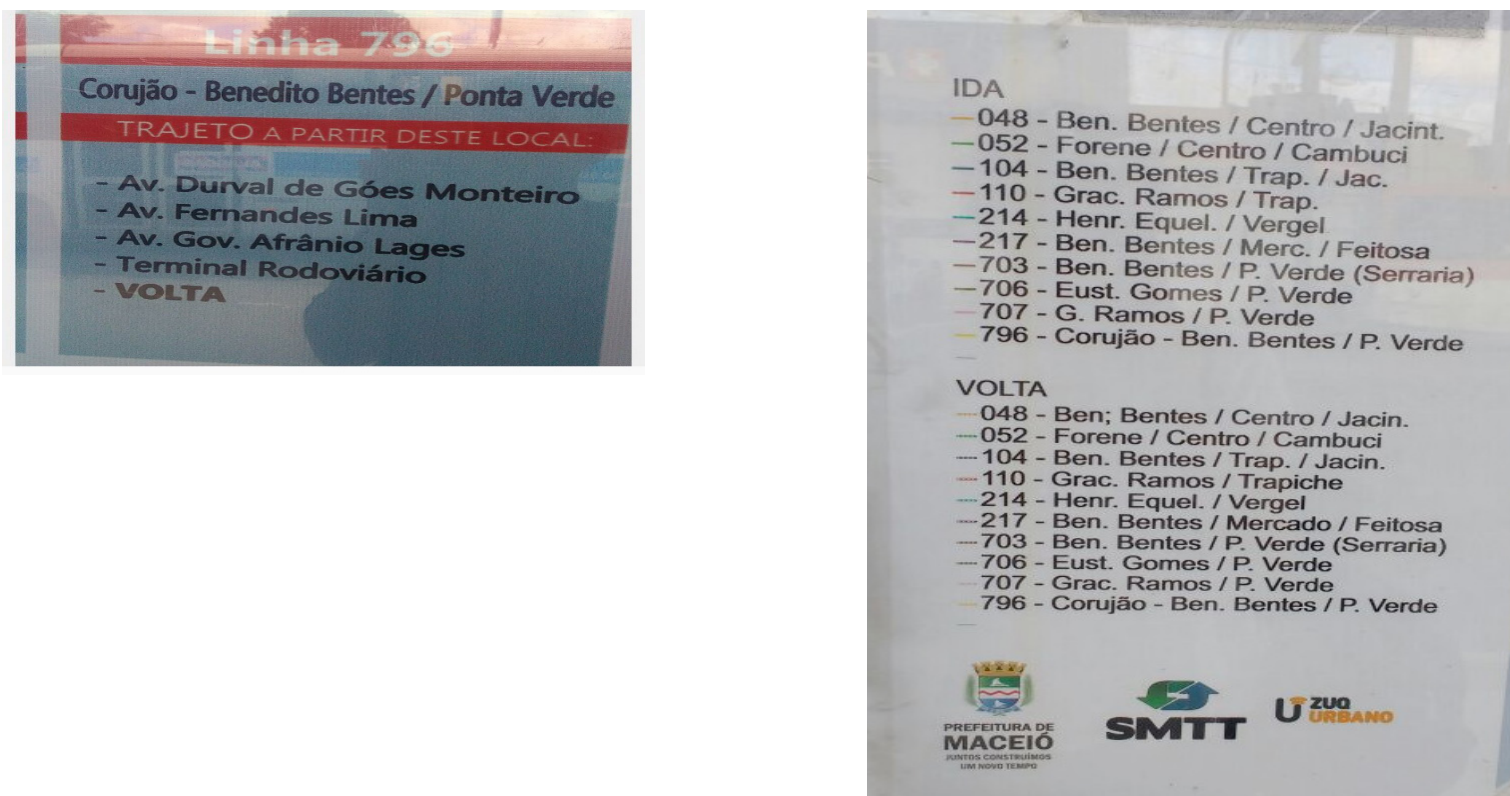
Diagramados desse modo, mostram para aqueles que estão lendo que letras com pesos diferentes servem para informar funções distintas. É notório que as tipografias usadas em ambos os pontos de ônibus são legíveis e de fácil compreensão, sendo assim um ponto positivo desse. Entretanto, considerando a acessibilidade a todas as pessoas, foram constatados alguns pontos negativos, tais como a ausência de informações em outros idiomas e em Braille.

Conforme Tom Froser e Adam Banks (2007), a cor influencia tudo, modelando, acidental ou intencionalmente, nossa percepção, facilitando a usabilidade pelo homem. Em vista disso, a divisão das linhas dos ônibus por cores pode ajudar ao usuário que já conhece a cor da linha e o seu trajeto, a focar apenas naquela coloração que deseja, já que em momentos de pressa as cores diferentes podem dialogar mais rapidamente com o homem, por chamarem mais atenção de maneira mais rapidamente e eficiente para uma visão breve. Neste aspecto, o ponto azul (Figura 6) apresenta o uso das cores auxiliando a diferenciação das linhas, onde as cores indicam destinos distintos. A priori, é importante destacar que a cidade de Maceió possui linhas de quatro cores diferentes, sendo estas: azul, vermelho, amarelo e verde, essas cores servem para identificar a qual empresa pertence os ônibus.

Figura 6- Diferenciação, através das cores das linhas de ônibus. Fonte: Elaborado pelo autor, 2017.

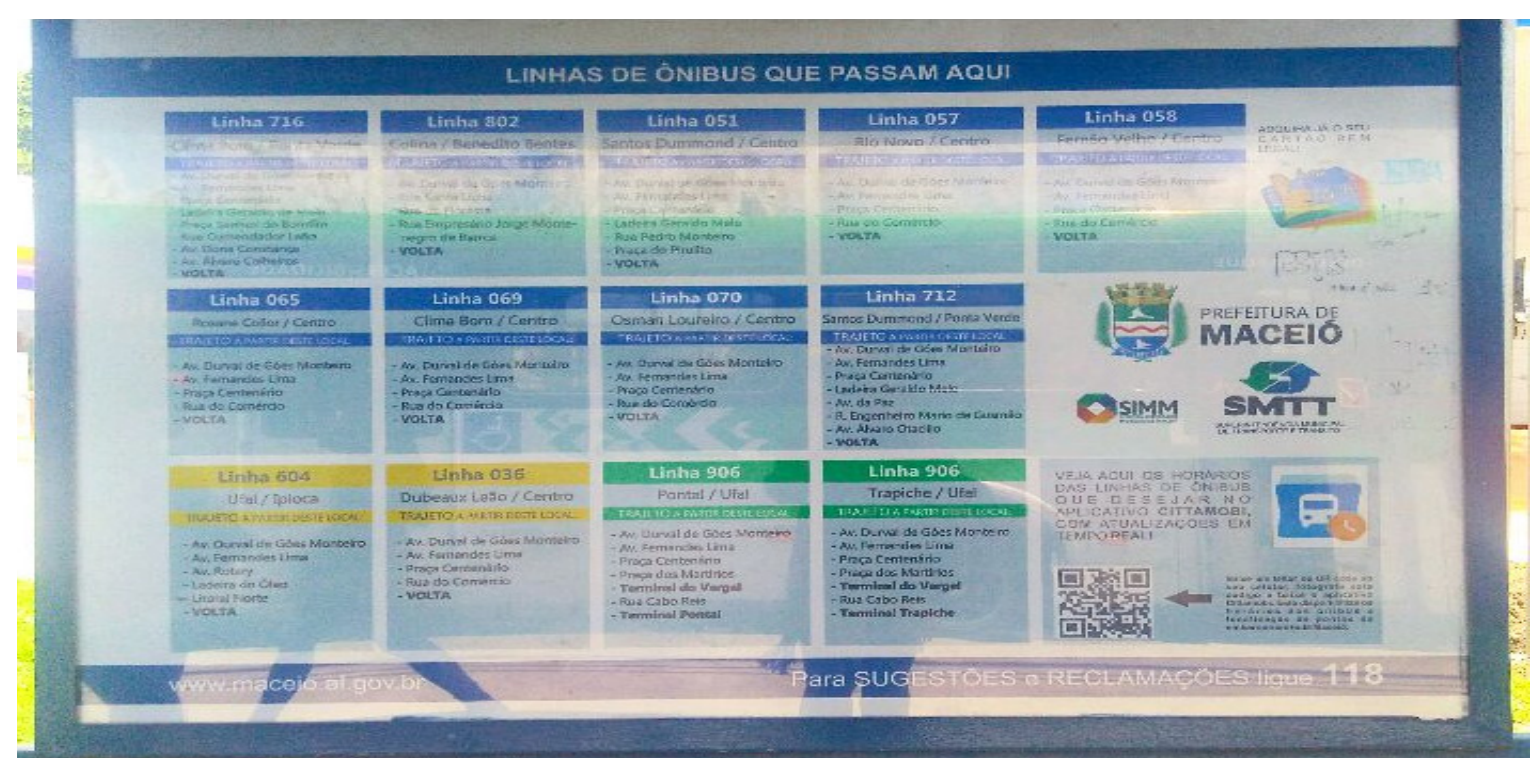

Apesar de se perceber que as cores ajudam a legibilidade através do contraste no ponto azul, promovendo assim a setorização e facilidade da informação por grande parte dos usuários; pode-se notar também que não necessariamente esta será facilmente interpretada por todos, tendo em vista que as cores são diferentemente percebidas pelas pessoas e que, segundo Vargas (2009), a sua tonalidade pode ser alterada de acordo com a incidência de luz, refletindo diretamente no espaço percebido, além de dificuldades genéticas de percepção da cor como o daltonismo.

Outro fator importante apontado pelos autores é a sinalização. No ponto branco pode ser observado no mapa, símbolo da parada de ônibus e símbolo de deficientes físicos. Onde o primeiro mostra o sistema viário das linhas de ônibus de Maceió e a localização do ponto de ônibus; o segundo o símbolo da parada de ônibus (Figura 7 e 8), que por sua vez é facilmente reconhecível até mesmo para aqueles que não sabem ler, e o símbolo de deficientes físicos, que está colocado de maneira a indicar o espaço entre os assentos do ponto de ônibus reservados para os cadeirantes. 
Figura 7- Sinalizações presente no ponto branco. Fonte: Elaborado pelo autor, 2017.

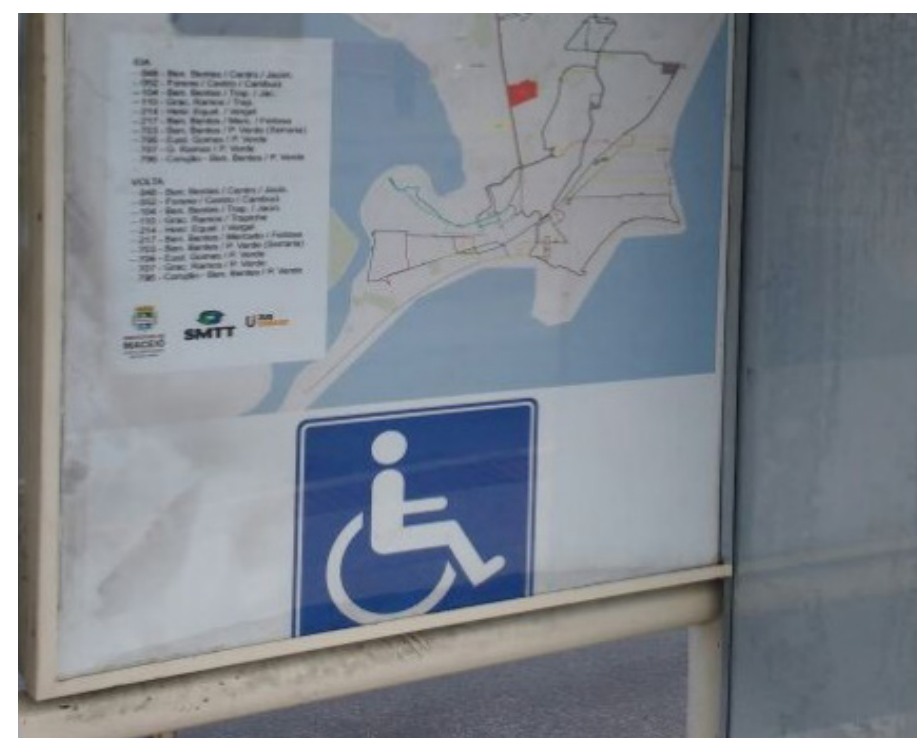

Figura 8- Parada de ônibus no ponto branco. Fonte: Elaborado pelo autor, 2017.

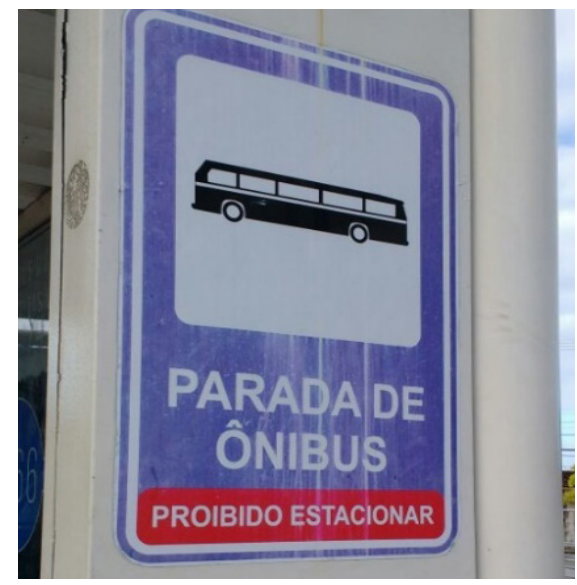

Os dois pontos de ônibus analisados neste trabalho possuem ainda o símbolo dos órgãos públicos: SIMM (Sistema Integrado Mobilidade Maceió), SMTT (Superintendência Municipal de Transporte e Trânsito) e da Prefeitura de Maceió (Figura 9). Além desses, há o símbolo do Cartão Bem Legal, que é o cartão vigente na cidade, que é dividido por cores para cada público e funcionam para pagar a passagem dos ônibus que circulam por toda a cidade.

Figura 9- Sinalizações presentes no ponto azul. Fonte: Elaborado pelo autor, 2017.

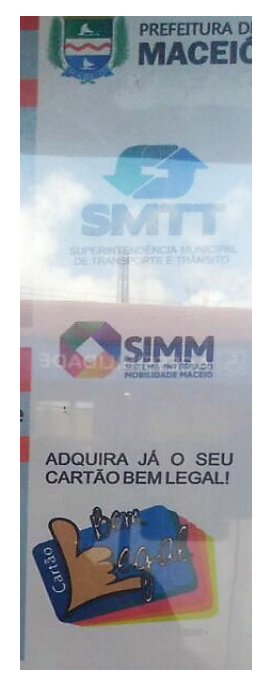


As sinalizações supracitadas foram colocadas de maneira apropriada para informar ao usuário os órgãos responsáveis por tal obra, e no caso do Cartão Bem Legal, para informá-las que podem adquirir este para facilitar no momento da viagem no transporte público.

Quanto à interatividade, percebe-se que esta vem sendo cada vez mais comum ao nosso cotidiano e é por este motivo que as empresas estão investindo cada vez mais neste segmento. Nos dois pontos de ônibus podem ser notados dois modos diferentes de expor esta interatividade para a população. Tanto no ponto branco quanto no ponto azul, há um espaço reservado para um QR code, que é um desenho feito especificamente para quando fotografado pelo celular, direcionar o usuário a utilizar um aplicativo chamado Cittamobi (Figura 10), que mostra quais ônibus transitam naquele local e quais são os horários específicos. Além disso, pode ser adicionado aos favoritos da sua linha de preferência, facilitando o uso frequente.

Figura 10- Símbolo do aplicativo Cittamobi. Fonte: Elaborado pelo autor, 2017.

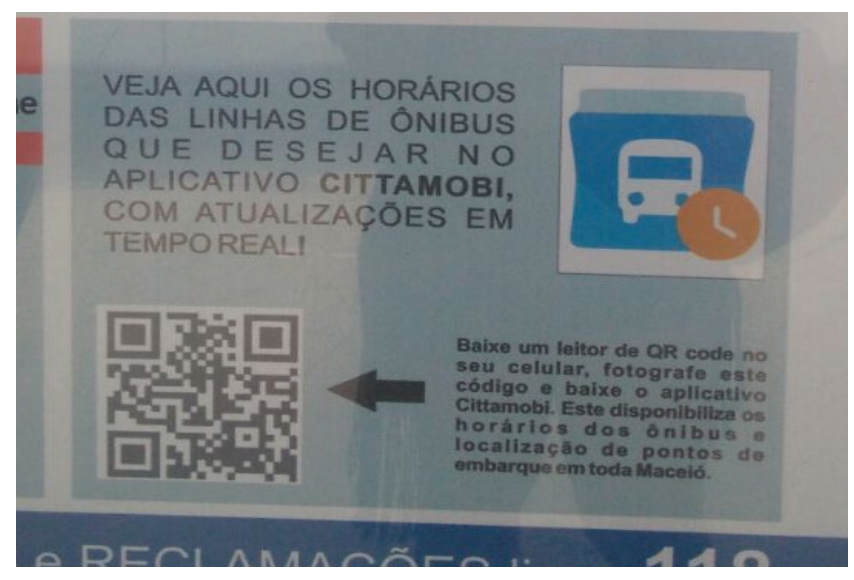

Além disso, em alguns modelos de celular, ao abrir a câmera deste, direciona a câmera para o QR code, mostrando na tela letras e números, que ao adicionadas direcionam para uma pesquisa no Google que mostra o aplicativo. Estes dois elementos interativos têm como objetivo facilitar o uso da população para que o tempo de espera do usuário do transporte público seja cada vez menor.

\section{CONCLUSÃO}

Após este estudo de caso foi notado que, os dois pontos de ônibus analisados mostraram com elementos visuais como: tipografia, cor e símbolos, que contribuem para a facilidade da percepção e usabilidade através de sistemas de informação. Entretanto, percebeu-se também, que algumas funções se limitam a uma parte da população que possui refinamento visual e repertório tecnológico mais abrangente. Além disso, constatou uma má acessibilidade a pessoas com deficiência visual ou baixa legibilidade;

Em relação às tipografias usadas, percebeu-se, de modo geral, que elas atendem à necessidade da tarefa de ser legível para o usuário. Contudo, segundo alguns designers, as tipografias serifadas são as mais indicadas para uma leitura explícita. No que concerne à cor, a divisão estabelecida no ponto azul por meio das cores foi bem-intencionada e atinge parcialmente o objetivo, visto que expressa de maneira imediata quais ônibus e empresas passam naquele ponto e nas demais localidades da cidade; porém podem causar efeitos de compreensão diferenciados em associação com elementos externos do entorno, a exemplo da luminosidade.

Ademais, com a evidenciação dos símbolos dos órgãos públicos é possível 
compreender que esses são responsáveis por tal atividade, deixando assim a população informada de quem é a incumbência de manter as paradas de ônibus organizadas, limpas e com informações importantes. Já a colocação da simbologia no painel de informações (tanto no ponto azul, quanto do ponto branco) relativo ao QR code para acessar o aplicativo Cittamobi, evidencia a importância do uso da tecnologia nos mais variados âmbitos. Tal abordagem mostra a preocupação com os usuários, para que estes fiquem o mínimo de tempo possível na espera do transporte.

Apesar de inúmeros pontos positivos apresentados neste estudo, foi verificado que para as minorias existentes na sociedade, faltam atributos para ajuda-las. Tais como as informações dos ônibus. Uma possível solução seria, através do design interativo, estudar as necessidades existentes deste serviço e assim, sanar os possíveis problemas para que toda a população seja contemplada com o melhoramento dos pontos de ônibus do sistema viário da cidade de Maceió.

\section{REFERÊNCIAS}

ABNT. Associação Brasileira de Normas Técnicas. NBR 9050: Acessibilidade a edificações, mobiliário, espaços e equipamentos urbanos. 2004.

ABNT. Associação Brasileira de Normas Técnicas. NBR 9241-11. Requisitos Ergonômicos para Trabalho de Escritórios com Computadores. 2002.

BACK, João Miguel. Manual para apresentação de trabalhos acadêmicos: graduação e pós-graduação. Canoas: Salles, 2004.

BANKS, A.; FRASER, Tom. 0 guia completo da cor. São Paulo: Editora Senac, 2007.

BEDROSSIAN, Rebecca. Environmental Graphic Design. Communication Arts. March/ April 2008. pag. 84/102.

BONNICI, P. Linguagem Visual. O misterioso meio de comunicação. Lisboa: Destartes Edições, 2000.

DUL, Jan. et. al. Ergonomia Prática. São Paulo: Edgard Blücher, 2004.

HEITLINGER, Paulo. Tipografia: origens, formas e uso das letras. Dinalivro. Lisboa, 2006.

IIDA, Itiro. Ergonomia: Projeto e Produção. São Paulo: Edgard Blücher, 2005.

MUNARI, B. (1977). Diseño y comunicacion visual. 3ª Edição. Barcelona: Editorial Gustavo Gili.

SALTZ, Ina. Design e Tipografia: 100 fundamentos do design com tipos. São Paulo: Blucher, 2010. 208p.

TWEMLOW, Alice. PARA QUE SERVE O DESIGN GRÁFICO? Barcelona: Editorial Gustavo Gil, 2007.

\section{VARGAS, Cláudia. A Influência da Iluminação em Projetos de Arquitetura}

destinados aos Serviços de Alimentação. 2009. 109p. Dissertação (Mestrado em Arquitetura). Universidade Federal do Rio de Janeiro. Rio de Janeiro.

NORMAN, Donald. O design do dia-a-dia. Rio de Janeiro: Rocco, 2002. 
Sobre os autores:

Kalana Barros Lins (graduanda), UFAL < kalanalins.kbl@gmail.com>

Maria Eduarda Ramos Cavalcanti Rosa (Mestra), UFAL <dudah.cavalcanti@gmail.com> 